\title{
Two types of mixed gonad dysgenesis (true hermaphroditism) of the dog - a clinical case
}

\author{
Georgi Georgiev $^{1}$
}

\author{
1. Department of Anatomy, Histology and \\ Physiology, Faculty of Veterinary Medicine, \\ University of Forestry - Sofia, Bulgaria;
}

\begin{abstract}
Mixed gonad dysgenesis or true hermaphroditism is the heaviest sexual chromosome syndrome in which one individual animal has simultaneously two fully functional types of reproductive tissue, which is presented with strong disorders in a dog's sexual development. With the expansion of castration of homeless and domestic dogs, as well as with the advancement in diagnostic imaging methods various genital abnormalities and dysgeneses in dogs of different breed affiliation can be detected. Hormonal imbalance, abnormal and delayed development, and ambiguous genital organs of a dog can be established. Sometimes they appear with nonspecific symptoms which are hard to differentiate from other disorders of the urinary and reproductive organs. The two types of true hermaphroditism as first manifest with male phenotype, second was develop with female phenotype were detected. The different types of sexually chromosome syndrome in the dog should be known and researched in dog's veterinary practice because such animals should be found and excluded from breeding and earlier reveal gives possible to treated.
\end{abstract}

Keywords: dog, sexual chromosome disorders, gonad dysgenesis, hermaphroditism, ambiguous genital organs, ovotestis.

\section{Background}

Depending on the expression of the histological state of the gonads true hermaphroditism in the human is of different types - the lateral type in which on the one hand there is a testis and on the other an ovary is more frequent, the unilateral type in which on the one hand there is an ovotestis and on the other a testis and ovary is the most frequent one, and the bilateral in which on the one hand there is an ovotestis and on the other again ovotestis or a dysgenetic testis which can be at any stage of testicular descent as the third 
possible type. There are several hypotheses reported accounting for these conditions. The first hypothesis states that an ovum is fertilized simultaneously by two different spermatozoa from two different individuals, the second holds it that the conditions can be caused by two ova being fertilized by two different spermatozoa with subsequent infusion of both zygotes, the third claims that the conditions can arise when an ovum and its polocyte are fertilized by two different spermatozoa with subsequent infusion (5). All this can be explained with the normal physiology of bitches during estrus when a large number of follicles are ovulated, and their behavioral reactions after several mattings and inseminations in a single, sometimes even with a within a window of a few hours with different male dogs (2).

The pathogenesis of abnormal development of the gonads is still not completely clear. In clinical genetics the condition in which two or more groups of cells with various genotypes in an individual are present, a state which is derived from one fertilized ovum, is designated as gonozom mosaicism $(5,6)$. Other authors suggest that this is caused by the translocation of genetic material from the $\mathrm{Y}$ - onto the $\mathrm{X}$-chromosome. Development of ovarian and testicular tissue is associated with genetic inactivation of the $X$-chromosome, the vehicle of translocated $\mathrm{Y}$-chromosome material (development of ovarian tissue), or with genetic inactivation of the $\mathrm{X}$-chromosome without translocated $\mathrm{Y}$-chromosome material (development of testicular tissue). Other specialists do not exclude the possibility for translocation of genetically active material from the Y-chromosome on the autosome (5).

Initially, during embryogenesis a fibrous-streak, ambiguous gonad is formed, which passes through an indifferent stage, consisting of paramesonephric (Müllerian ducts) and mesonephric (Wolffian ducts) channel system, degenerative medullary cords, primordial germ cells and islets of follicular cells (6, 8, 9, 15). This gonad is called an ovotestis at this stage and has primary talents for both reproductive tissues $(6,8,9,15)$. Differentiation of the testis occurs under the influence of the Sry gene (testis determining factor) on the Y-chromosome. Without the expression of products of this gene, the indifferent gonad develops somewhat later into an ovary (6). In male embryos, transcripts of the Sry gene only become detectable in the genital ridge at the onset of testis differentiation. Neither the expression of the Sry gene in the testis primordium, nor subsequent testicular development, is dependent on the presence of germ cells (6). Sry triggers testis formation by inhibiting Dax-1, a member of the nuclear receptor family, which is also expressed in the indifferent gonad at the same time $(6,9,15)$. The inhibition of Dax-1 is necessary for a genetically male gonad to express its sex phenotypically and develop into a testis. In a female embryo, the expression of Dax-1, in the absence of Sry gene, suppresses the formation of a testis and allows the indifferent gonads to develop into ovaries. The medullary cords transform into solid testicular tubules composed of primitive germ cells centrally and presumptive sustentacular cells or Sertoli cells peripherally (6). This sexual differentiation was studied in pig embryos by Pelliniemi, 1985 (6, 14). The Sartoli cells produce Müellerian inhibitng hormone and Antimüellerian inhibiting substance which suppress the development of the paramesonephric ducts. In the mesenchyme between the testicular cords, the first generation of androgen-producing Leydig cells appear $(5,6,7)$. Under the influence of testosterone from the embryonic Leydig cells, the mesonephric duct continues to develop and becomes the main drainage system for the testis and epidydymis. Contrary to testicular development, the presence of viable germs cells is necessary for ovarian differentiation $(5,6,7)$. If the primordial germ cells fail to reach the genital ridges, the gonadal anlagen regress and streak ovaries result. If the primordial germ cells have reached the genital ridge, they remain concentrated in the outer (cortical) region of the future ovary. The medullary region also contains some primordial germ cells that become enclosed in primitive sex cords, but in a far less well developed state than in the testis (6). If ovaries are present, or if gonads are absent, the sexual duct system differentiates into a female phenotype. The absence of Müllerian inhibiting substance allows 
the Müllerian duct to develop into the major structures of the female reproductive tract $(6,9,15)$. Canine female pseudohermaphrodites have bilateral ovaries. Müllerian or paramesonephric duct derivatives develop normally, forming oviducts, a uterus, and a cranial vagina. Androgen-responsive organs are, however, masculinized during development. Masculinization ranges from mild clitoral enlargement to nearly normal male external genitalia with an internal prostate. Male pseudohermaphroditism is more common than female with most affected dogs have undescended testes, a female duct system, and male external genitalia $(6,10,16,17)$. Animals with true hermaphroditism, which is an extremely rare condition, possess both ovarian and testicular tissue either separately or in combination $(5,6,10,16,17)$. In cases of genetic mosaicism, both an ovary and a testis can be present separately. In other cases, ovarian and testicular tissues form a single organ called an ovotestis $(5,6)$. Normally in the male the fused caudal ends of the paramesonephric duct are commonly seen in the prostate, where they form the small midline prostatic utricle. This is regarded a rudimentary uterine primordium. In some cases of male pseudohermaphroditism, the prostatic utricle is enlarged to a uterus-like structure. This phenomenon may be referred to as persistent Müllerian duct syndrome, which is characterized by the formation of a uterus and uterine tubes $(6,10,16,17)$. This condition has been reported in male Miniature Schnauzers and the Basset Hound. Affected dogs have bilateral oviducts, a complete uterus with cervix, and a cranial portion of the vagina. An intersex condition that may be a parallel to the persistent Müllerian duct syndrome has also been reported in Persian cats (6). Appearance of ovotestes, mixed internal gonad ways, normally functioning ovaries and descended testes were explained by this embryopathogenesis $(8,9,15)$..

\section{Case Description}

Case number 1: a male dog, 3 years, mixed breed, with weight of $35 \mathrm{~kg}$. In this case almost normal development and descent into the scrotal sac of the left testis and epididymis with minimal hypoplasia were observed through an autopsy (fig.1 and 3). The ductus deferens was normally passable but ended on the tip of the left uterine horn (fig. 3 and 6). On the right side an indifferent gonad - an ovotestis was found with a rudimentally developed channel system (Wolffian, mesonephric duct) but it was detained into the abdominal cavity within normal location of the ovary bitches, caudally positioned behind the right kidney with elongated ovarian suspensory and proper ligaments, quite normal lig. teres uteri directed towards inguinal canal, with ovarian tissue and well developed paramesomephric ducts (fig. 3 and 4). Clearly visible were Müllerian duct derivatives, a well developed uterus with horns, body, cervix and the cranial part of the vagina (fig. 1 and 5). The end, thin orifice of the vagina opens into the dorsal wall of the urogenetal sinus (male urethra) between very well developed lobes of the body of a prostate gland and located into the pubic region of the abdominal cavity (fig. 5 and 6). The male urethra is also passable, covered by the prostate gland, with the penis in this dog of quite normal size and structure (Fig. 1, 5 and 6). This development is under the influence of testosterone. It is likely that the development of this descended testicle has led to normal spermatogenesis and this male individual was able to perform normal insemination of bitches, so that these sexual developmental disorders are genetically transmittable to the next puppy generation.

Case number 2: a female dog, 5 years, mixed breed, with weight of $30 \mathrm{~kg}$. In this case on the left side a normally situated and well developed ovary is found in the ovarian bursa, but on the right side a bigger testis with a strong channel system and enlarged, tortuous and extended blood venous vessels into its tunica albuginea and developed epididymis was established (fig.2). This testis is detained in the abdominal cavity, which is the normal position of indifferent embryonic gonads, and the ability of testis to 
descend was blocked (fig.2). The uterus is of normal size and passable with a well-developed horn, body and cervix. a normal vagina and external genital organs were observed.

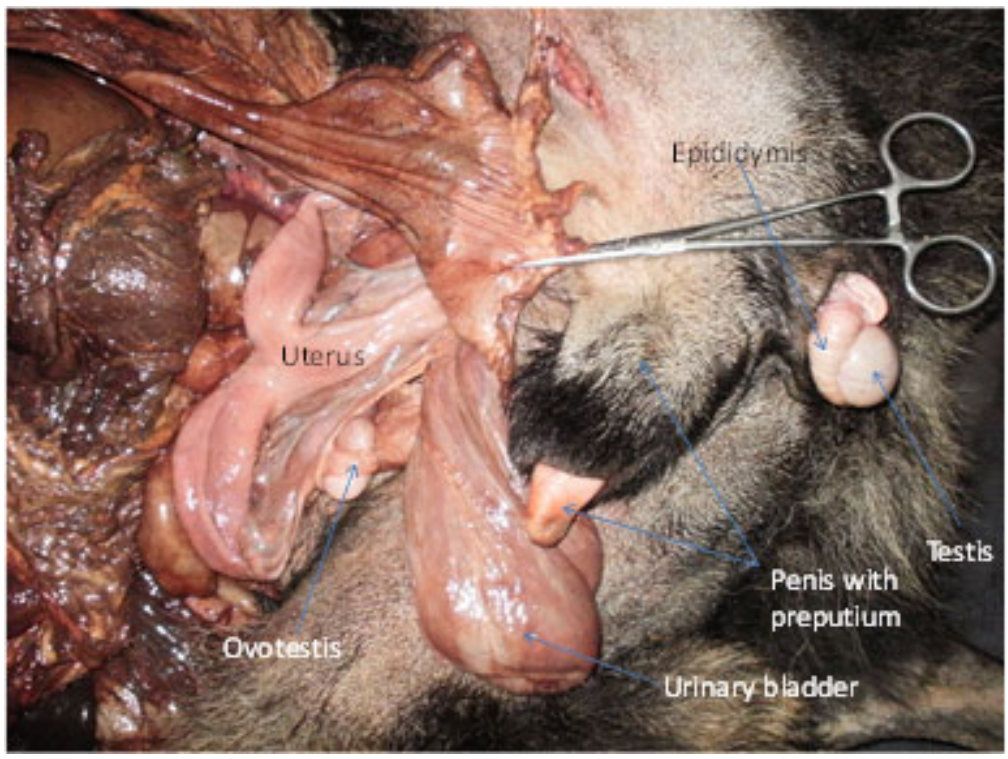

Fig. 1. Genital organs of the dog, abdominal cavity, ventral view

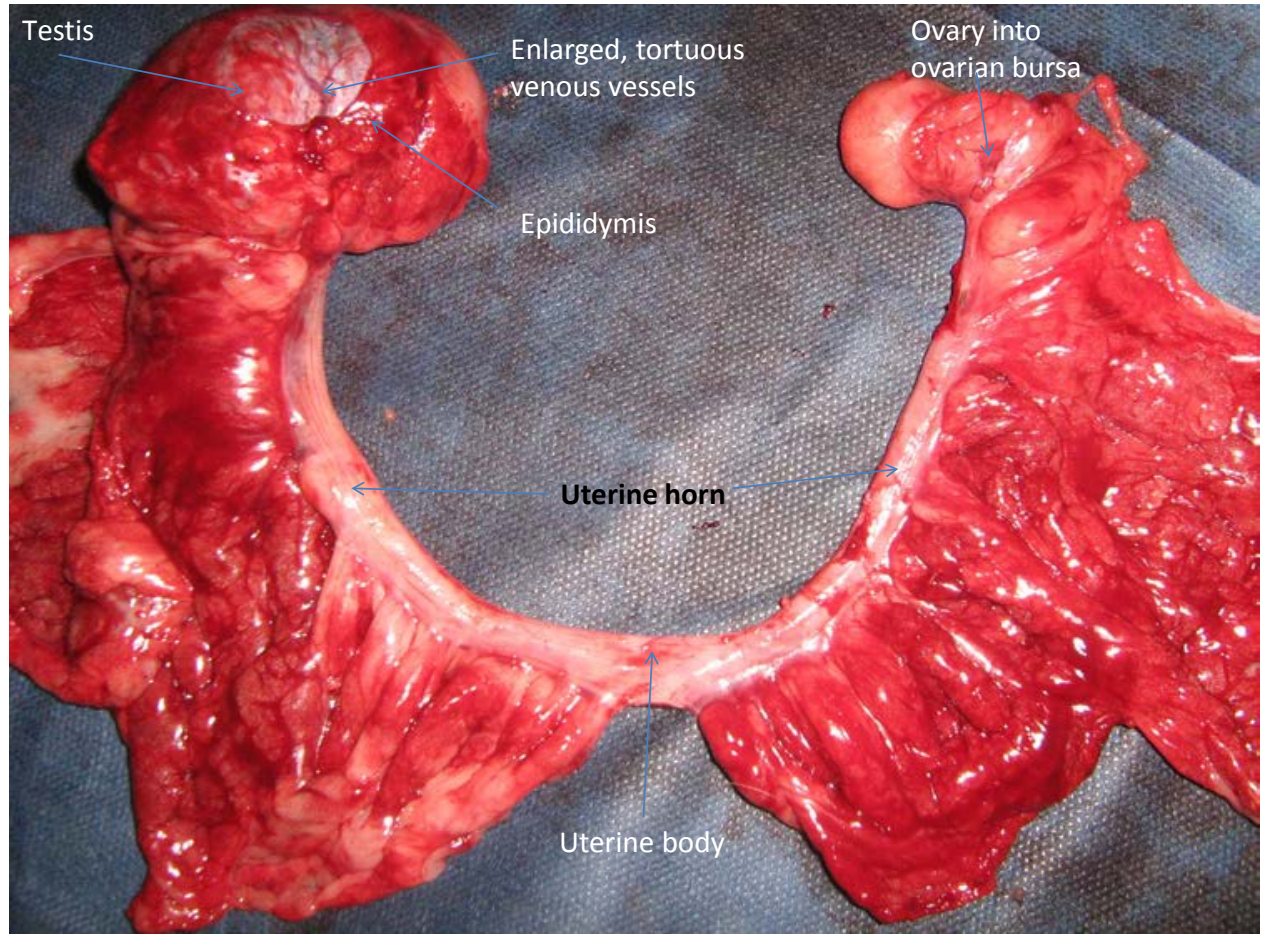

Fig. 2. Internal genital organs of the dog, ventral view 


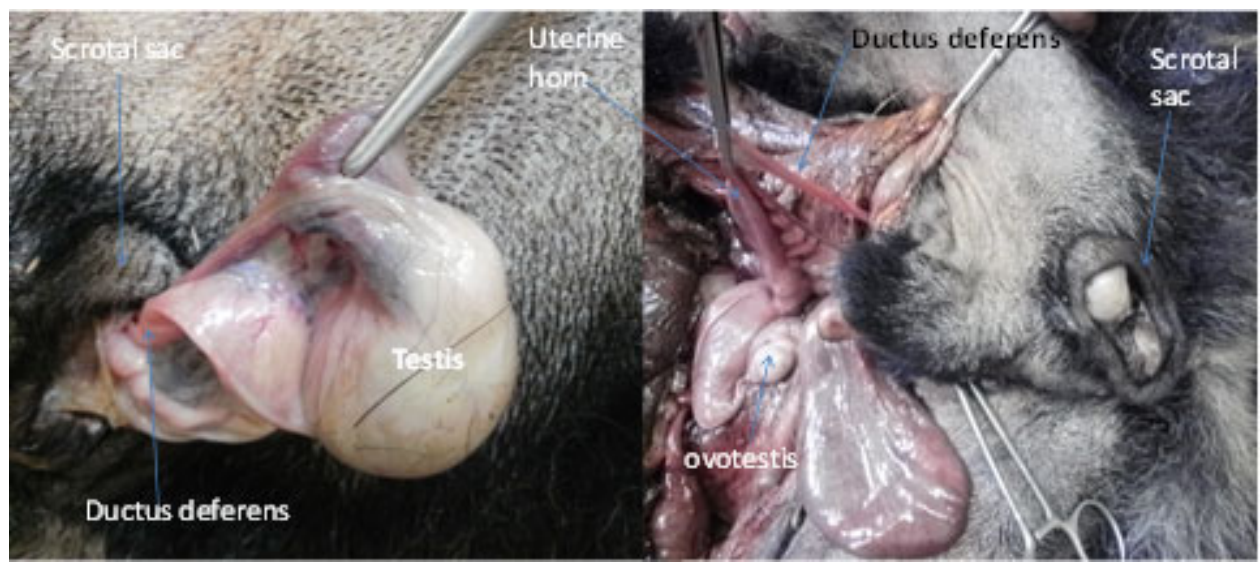

Fig. 3. Genital organs of the dog, ventral views

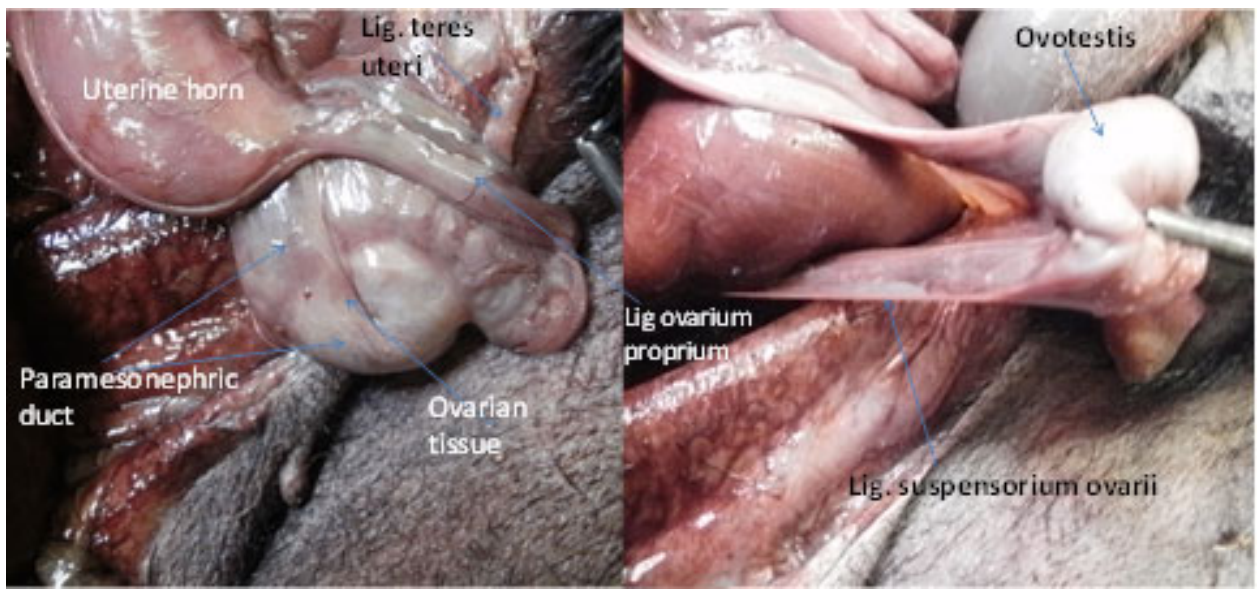

Fig. 4. Genital organs of the dog, ventral views

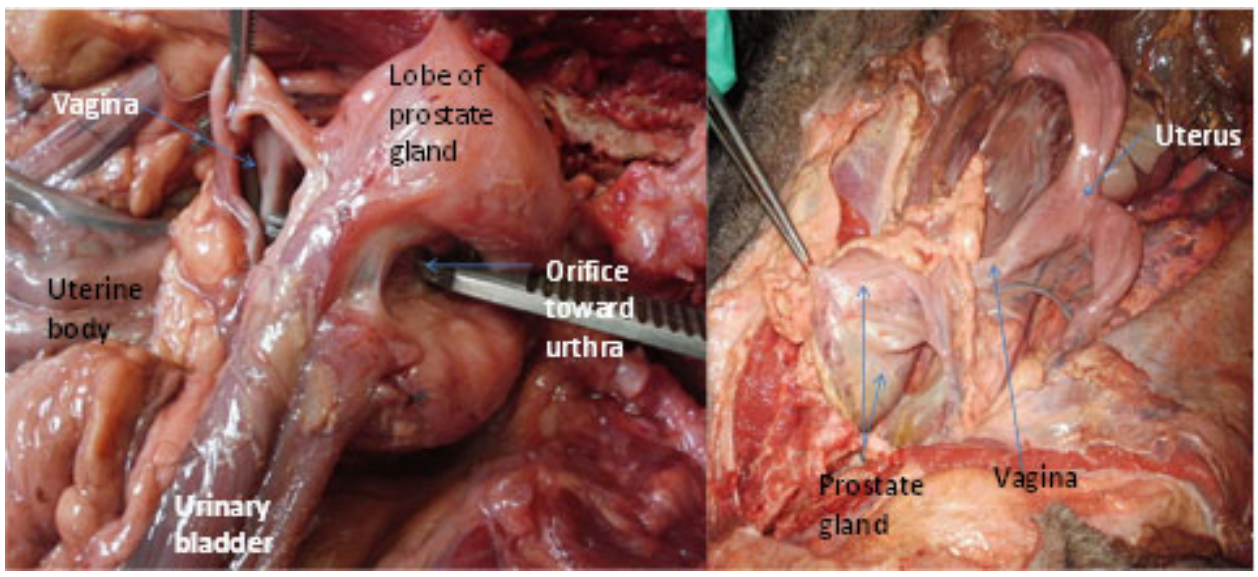


Fig. 5. Genital organs of the dog, ventral views

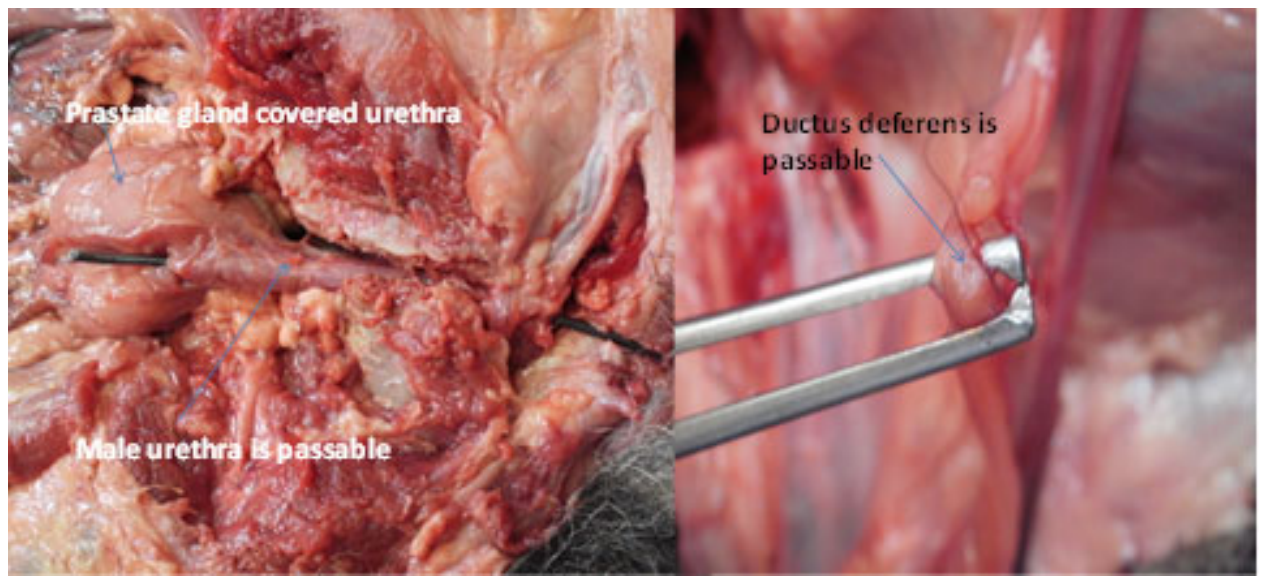

Fig. 6. Genital organs of the dog, ventral views

\section{Discussion}

In humans mixed gonad dysgenesis is manifested as lateral in $30 \%$ and as unilateral in $45 \%$ of patients as reported by Genkova et al., 1989 (5). Bilateral dysgenesis is found only in $25 \%$ according to Bozadzieva et al., 1981 (3). In bilateral hermaphroditism internal genital ways are of the mixed type. Usually Müllerian duct derivatives are well developed but with hypoplasia, while the Wolffian mesonephric duct remains in a rudimentary phase in its development. The testis shows different degrees of maturity but spermatogenesis is extremely rarely found. The ovaries are well developed and have primordial follicles, bloomers and mature follicles and a well-formed luteum body (5). A different type of gonad dysgenesis in humans is and asymmetrical mix which is characterized with intersex genitals - dysgenetic testis from one the one hand and a fibrous-streak indifferent gonad on the other hand into the abdominal cavity. The external genital organs could show different conditions: from weak hypertrophy of the clitoris to male reproductive organs with hypospadia. Secondary sex signs usually developed physical characteristics of males, but lag in their own full development (5).

A persistent Müllerian duct syndrome which is characterized by the formation of a uterus and uterine tubes in the male Miniature Schnauzers and the Basset Hound has been reported. A similar condition has also been reported in Persian cats $(6,10,16,17)$.

Abnormalities of gonad sex - XX sex reversal (true hermaphroditism) in the American cocker spaniel is inherited as an autosomal recessive trait. Similar familial disorders have been reported in the German shorthaired pointer, English cocker spaniel, Beagle, Chinese pug, Kerry blue terrier and Weimaraner. The hypospadia is considered inherited in the Boston terrier $(6,10,16,17)$. Testicular feminization is another sex disorder, reported in pigs, cats and Canarian horned goats $(1,10,16,17)$. 
Physical examination findings in the animal could be normal or hypoplastic vulva, vulvar discharge and perivulvar dermatitis, large clitoris or clitoris with clitoral bone in the dog, which sometimes is a normal find in bitches $(4,17)$, unilateral or bilateral cryptorchidism, scrotal testes, normal and hypoplastic penis and prepuce, normal and abnormal location of the urethral meatus, with possible abdominal mass and dermatologic signs of hyperestrogenism in males $(6,10,11,12,13,16,17)$. Routine radiography and ultrasonography may be of diagnostic value in phenotypic females or males in which an abdominal mass (testicular neoplasia) is suspected, or in phenotypic males with signs referable with pyometra $(6,10,11$, $12,13,16,17)$. Contrast studies of the lower urogenital tract can be useful in the diagnosing of female pseudohermaphroditism. Through histopathologic examination of the gonads the following conditions were established: a nearly normal architecture, a dysgenetic one and a combination of ovotestis. Infertility, sterility, urine incontinence, cystitis, testicular neoplasia and pyometra appear as possible complications due to sexual development disorders in the $\operatorname{dog}(6,10,11,12,13,16,17)$. Some authors have reported that ambiguous gonads develop highly malignant tumors in humans - seminom, gonadoblastom, dysgerminom (5). Many authors recommend gonadectomy or hysterectomy as prevention or radical decision at the establishment of gonad dysgenesis on account of following neoplasms developments, or alternatively suggest sterilization as a measure for the removal of carrier animals with heritable disorders from the breeding program $(6,10,11,12,13,16,17)$.

In the first of our cases the condition is similar to what is reported as male pseudohermaphroditism with an enlarged prostatic utricle - uterus-like structure which is defined as persistent Müllerian duct syndrome in the $\operatorname{dog}(6,10,17)$. This condition is closest to a bilateral mixed gonad dysgenesis with prevalence of the male phenotype which is described in humans where there is mixing of internal roads genitalia (5). On one hand there is a typical indifferent gonad - ovotestis, on the other a descended testicle is also present (5), which has a slight hypoplasia and probably in its medullary region contains some primordial germ cells in cords saved into this dysgenetic testis because similar cells but in a far less well developed state are found in the dysgenetic ovarian medulla $(6,14)$. This condition is sismilar to asymmetrical gonad dysgenesis in humans, where there are indifferent fibrous-steak gonad and dysgenetic testis with well developed male external organs but the internal genital pathways are not mixed (5).

In the second of our cases the condition is nearest to a lateral gonad dysgenesis with prevalence of the female phenotype which is generally detected in humans. On one hand there is a typical normal ovary, on the other hand an enlarged testis without descent is also detected $(5,10,17)$.

\section{Conclusion}

The mixed bilateral and lateral gonad dysgenesis or true hermaphroditism in dogs was observed which was readily diagnosed by radiography or ultrasonography. The establishment of the latter condition leads to immediate gonadectomy because on one hand this is a prevention against developing later malignancies and on the other hand these genetic diseases are transmitted in future generations. Through these two cases, we hope to help for the identification of such occurrences during surgery by veterinary practitioners and recommend more comprehensive external physical examination and caution in order to detect sexual development disorders in dogs.. 


\section{References}

1. Batista M., F. Gonzalez, F. Cabrera, E. Palomino, E. Castellano, P. Calero, A. Gracia.True hermaphroditism in a horned goat with 60XX/60XY chimerism. Can. Vet J., 41, 562-564, 2000.

2. Bajchev J., P. Parvanov, I. Nikolov, M. Sabev, Z. Shindarska. Artificial insemination and andrology in the livestock. Videnov and son ed. Sofia, 2007.

3. Bozadjieva E., P. Genkova, S. Dokumov. Genetics and immunogenic aspects of endocrine disease. Medicine and gymnastics, Sofia, 223, 1981.

4. Evans H.E., A. De Lahunta. Miller's Anatomy of the Dog. Fourth edition. Saunders\&Elseiver, St. Luis, Missouri, 2013.

5. Genkova P. I., Georgieva W. L., Koev D. J., Karnolski I. N., Lalchev S. G., Obrecova V. C., Coneva M. T. Clinical genetics of the internal disease. Medicine and gymnastics, Sofia, 1989.

6. Hyttel P., F. Synowatz, M. Vejlsted, K. Betteridge. Essential of Domestic Animal Embryology. Saunders\&Elsevier, 2010.

7. Josso N.B., J. V. Picard, J. L. Dachieux, M. Courot. Initiaton of production of anti-Müllerian hormone by the fetal gonad. Arch. Anat. Microscop. Morphol. Exp., 74, 96-100, 1985.

8. Krastev H., S. Vitanov. Embryology. Zemizdat, Sofia, 1994.

9. Latshaw W. K. Veterinary developmental anatomy. A clinical approach. B.C. Decker Inc, South Service Road, Burlington, Ontario, Canada,1987.

10. Lyle S.K., Meyers-Wallen V.N. Sexual Development Disorders. The 5 minute veterinary consult canine and feline. Williams\& Wilkins, Baltimore, USA, 1058-1059, 1997.

11. Meyers-Wallen V.N., Patterson D.F. Disorders of sexual development in dogs and cats. In: Current veterinary therapy X. Philadelphia, WB Saunders, 1261-1269, 1989.

12. Meyers-Wallen V.N., Patterson D.F. Disorders of sexual development in dogs and cats. In: Current veterinary therapy in theriogenology. 2nd ed. Philadelphia, WB Saunders, 567-574, 1986.

13. Meyers-Wallen V.N. Genetics of sexual differentiation and anomalies in dogs and cats. J Reprod Ferr Suppl., 47, 441-452, 1993.

14. Pelliniemi L.J. Sexual differentiation of the pig gonad. Arch. Anat. Microsc. Morph. Exp., 74,76-80, 1985.

15.Sadler T. W. Langman`s medical embryology. Williams\& Wilkins, Baltimore, USA, 1995.

16. Saperstein G. Congenital abnormalities of internal organs and body cavities. Vet. Clin. North Am., Food Anim. Pract., 9, 115-125, 1993. 
17. Tilley L. P., F. W. K. Smith, Jr. The 5 minute veterinary consult canine and feline. Williams\& Wilkins, Baltimore, USA, 1997.

\section{Corresponding author:}

Georgi Georgiev

Sofia Bulgaria 1, Tsarigradsko shosse Blvd. 73

tel: +359 898743055

e-mail: dr_gigeorgiev@abv.bg 